\title{
Percutaneous coil embolisation of congenital hepatic arteriovenous malformations in two patients with congenital heart disease and review of the literature
}

\author{
Al-Ata Jameel ${ }^{1,2}$, Arfi Muhammed Amin ${ }^{1 *}$, Hussain Arif', Kouatli A. Amjad¹ \\ ${ }^{1}$ King Faisal Specialist Hospital \& Research Centre, Jeddah, Saudi Arabia; *Corresponding Author: ped cardiologist@doctor.com \\ ${ }^{2}$ King Abdul Aziz University Hospital, Jeddah, Saudi Arabia
}

Received 30 March 2010; revised 26 April 2010; accepted 27 April 2010.

\begin{abstract}
Congenital hepatic arterio-venous malformations (AVM) are rare vascular anomalies and have rarely been reported in the presence of congenital heart disease. The reported cases are mostly hemangiomas fed either by the hepatic artery itself or by one of its branches. We present two unique hepatic AVM cases in the presence of congenital heart defects in which the AVM was not fed by the hepatic arterial system. Transcatheter coil embolisation was successfully carried out in both of them by using non-detachable Gianturco coils. Complete occlusion was achieved without any sequel.
\end{abstract}

Keywords: Arterio-venous Malformation; Trans-Catheter Embolisation; Congenital Heart Disease

\section{INTRODUCTION}

Hepatic vascular malformations comprise about $10 \%$ of all cases of abnormal vascular connections within the hepatic parenchyma [1]. These are further classified into fast-flow (AVMs, arterio-portal fistulas), slow-flow (porto-systemic shunts, venous lymphatic malformations) and combined forms [2]. Hepatic AVMs should be differentiated from the benign hepatic vascular tumors (HVT) when an AVM can occur within the tumor mass itself. Unfortunately, the terms hemangioma and arterio-venous malformation (AVM) have been confused or used interchangeably in the literature [3]. Histologically, HVT are derived from mesenchymal tissue elements and are classified as hemangioendothelioma (HE) or cavernous hemangioma (HC) [4,5]. More recently, these tumors are classified into infantile hemangioendothelioma (IHE) and arteriovenous malformations (AVM)
[6,7]. Hemangioendothelioma progresses in the first year of life and then regresses spontaneously. On the other hand hepatic AVMs (in the absence of HVT) result from abnormalities in the formation of blood vessels that shunt blood through direct arterio-venous connections without abnormal neoplastic tissue between the anomalous vessels. So AVMs are neither tumors with growth potential, nor capable of regression [1,6] but have a higher and not well documented mortality rate [8]. On the contrary the HVT has an age related tendency of malignancy [5].

Hepatic AVMs are diagnosed either incidentally on abdominal sonography for other reasons or may result in congestive heart failure (CHF) due to significant intra-hepatic shortcircuiting of blood. Ultrasonography (US) and magnetic resonance imaging (MRI) are useful diagnostic tools $[9,10]$ but selected angiography is an optimum diagnostic modality. Hepatic AVMs have been reported in association with hemangiomas, and hereditary hemorrhagic telangiectasia but rarely been reported in association with congenital heart defects. We encountered two such cases which are briefly described.

\section{CASE 1}

This young infant presented to our services at two months of age (weight $=5 \mathrm{~kg}$ ) with complaints of bluish discoloration of lips and nails since early life. Pertinent physical examination features included significant oxygen desaturation to $58 \%$ on room air, normal SI, single SII and systolic ejection murmur III/VI at the left upper sternal border. He was finally diagnosed as a case of complex congenital heart disease in the form of double inlet left ventricle, hypoplastic right ventricle, transposed great arteries, large ventricular septal defect, and severe sub-pulmonary/pulmonary stenosis. Palliative balloon atrial septostomy was carried out for adequate inter-atrial mixing, which improved the oxygen saturation to $80 \%$ 
on room air. He was then discharged in a stable condition.

At the age of two years (weight $=12.5 \mathrm{~kg}$ ) he underwent diagnostic cardiac catheterization for hemodynamic assessment and delineation of pulmonary artery anatomy as a pre-Glen assessment. Descending aortograpgy, done to rule out aorto-pulmonary collaterals, revealed incidentally a significant hepatic AVM. The

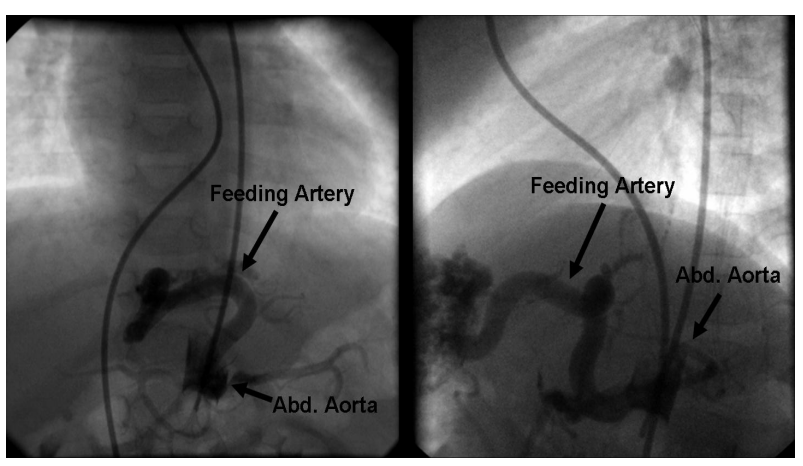

Figure 1. Abdominal aortogram in straight antero-posterior and lateral projections, showing feeder artery arising from abdominal aorta and supplying the arterio-venous malformation. $A b d=$ abdominal.

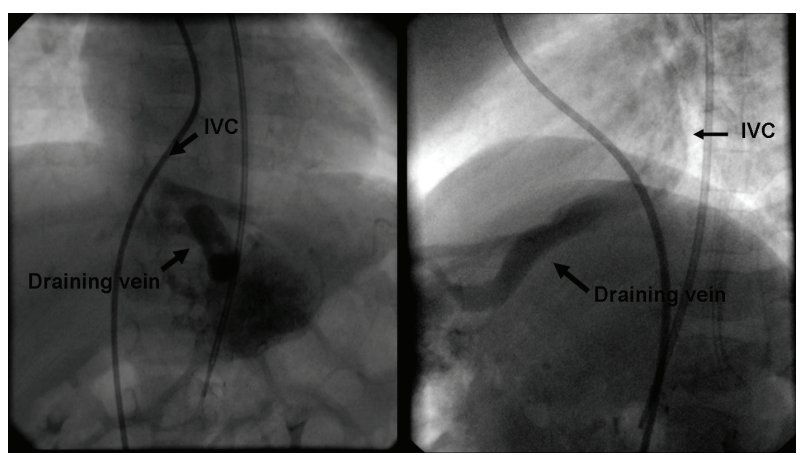

Figure 2. Abdominal aortogram in straight antero-posterior and lateral projections, showing the malformation draining through a vein (draining vein) to the hepatic portion of inferior vena cava (IVC).

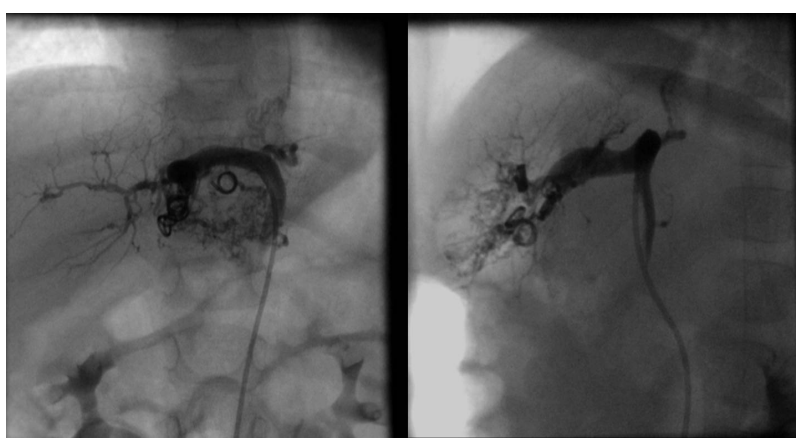

Figure 3. Selective angiogram in the arterio-venous malformation (AVM) in straight antero-posterior and lateral projections after coil embolisation, showing almost complete occlusion. feeder artery was seen arising from the abdominal aorta (Figure 1) and the malformation was seen draining into the hepatic portion of inferior vena cava (Figure 2). The AVM was occluded by deploying multiple (four coils of $5 \mathrm{~mm}$ and one coil of $3 \mathrm{~mm}$ diameter) non-detachable Gianturco coils (Mreye embolisation coils; Cook: William cook, Europe) retrogradely through a 4-French end-hole catheter. No complications were encountered and post occlusion angiography confirmed near complete occlusion (Figure 3). At the same time he underwent lateral tunnel fenestrated Fontan procedure. Lately he was seen in the out-patient clinic at the age of 3 years (weight $=15.5 \mathrm{~kg}$ ). He was doing fine without significant complaints and his oxygen saturation ranged between $88-90 \%$ on room air.

\section{CASE 2}

This was the product of 35 week gestation, born (weight $=2.1 \mathrm{~kg}$ ) to a 35 year old mother with good Apgar score at one and five minutes. Her physical features were consistent with Down syndrome (confirmed by chromosome analysis). At day one of age she developed congestive heart failure and was electively intubated because of significant respiratory distress. Physical examination revealed apparent distress with retractions, heart rate of $200 / \mathrm{min}$, respiratory rate of $78 / \mathrm{min}$, and liver palpable 4 $\mathrm{cm}$ down the right costal margin. Chest roentgenogram showed cardiomegally and increased vascular markings. Echocardiography confirmed her having juxta-ductal coarctation of the aorta (gradient $=20 \mathrm{mmHg}$ ). Incidentally, an abnormal flow reversal was also seen at the transverse arch level in the absence of aortic insufficiency. The reason for this flow reversal could not be ascertained. She was taken to the catheterization laboratory in view of looking for the reason of this abnormal flow reversal in the aortic arch and possible balloon angioplasty of coarctation. Pull back of catheter from ascending to the descending aorta revealed a pressure drop of only $14 \mathrm{mmHg}$ from ascending to descending aorta. Aortic angiogram revealed a large aneurysmal and a bit tortuous vascular channel (maximum diameter of $3 \mathrm{~mm}$ ) arising from the right internal mammary artery, supplying the right lobe of the liver (Figure 4) and draining to the hepatic portion of IVC (Figure 5). Small Patent ductus arteriosus (PDA) was also seen. This vascular malformation was successfully occluded by deploying multiple (4 coils of $3 \mathrm{~mm}$ and one coil of $2.5 \mathrm{~mm}$ diameter) non-detachable Gianturco coils (Mreye embolisation coils; Cook: William cook, Europe) retrogradely through an end-hole catheter. Repeat angiography confirmed complete occlusion of the AVM (Figure 6). Subsequently the patient was successfully extubated and 
discharged in a stable condition.

She was followed regularly in the out-patient clinic without much complaint till the age of 16 months, when she started having shortness of breath on feeding and on regular activities. Physical examination revealed absent femoral pulses and a non-invasive blood pressure difference of $45 \mathrm{mmHg}$ between the upper and the lower limbs. Echocardiography confirmed the development of significant coarctation with a gradient of $40 \mathrm{mmHg}$

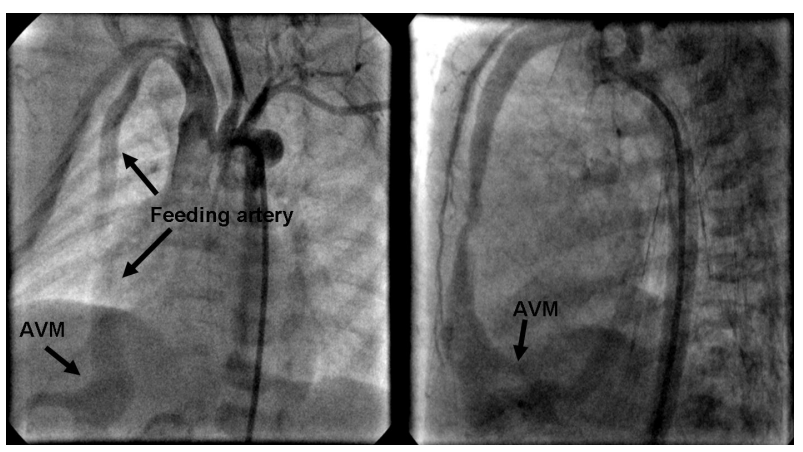

Figure 4. Aortic angiogram in LAO $15 / \mathrm{Cr} 20$ and lateral projections showing dilated and tortuous internal mammary artery, feeding the arterio-venous malformation (AVM) to the right lobe of the liver.

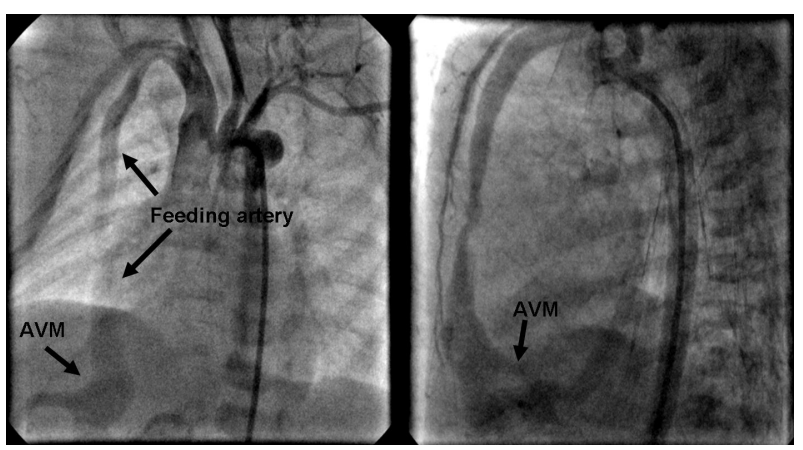

Figure 5. Selective angiogram in the internal mammary artery in straight antero-posterior and lateral projections showing the malformation draining through the hepatic portion of the inferior vena cava (IVC). A portion of the right atrium (RA) is also opacified.

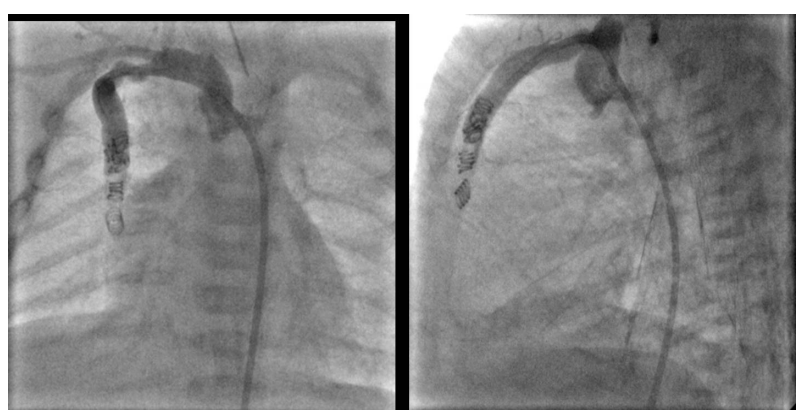

Figure 6. Selective angiogram in the internal mammary artery in straight antero-posterior and lateral projections after the coil embolisation of the malformation, showing complete occlusion. across it. Successful balloon angioplasty of the coarctation was carried out at that time. The PDA had already been occluded spontaneously.

Lately she was seen in the out-patient clinic at the age of 34 months (weight $=17 \mathrm{~kg}$ ). She was doing fine without any complaints and there was no significant blood pressure difference between the upper and the lower limbs.

\section{DISCUSSION}

Hepatic AVM can be of three types: a direct communication between a systemic artery and a hepatic vein (hepatic AV fistula); a communication between the hepatic artery and the portal venous system (hepatoportal fistula); multiple arterio-venous miocrofistulae as part of the hereditary hemorrhagic talengiectasia or hemangioma. There have been many reports in the literature discussing all aspects ranging from diagnosis to treatment options for hepatic AVMs, but most of the reports have included hemangiomas and other proliferative disorders under this condition. Ours are true AVMs, (hepatic AV fistula) in the sense that there is a solitary feeder artery supplying the AVM and then draining through a venous channel to the hepatic portion of inferior vena cava without significant capillary phase, resulting in high cardiac output state. Also an association of hepatic AVM with cyanotic congenital heart disease has never been reported before. Keeping in view the importance of the condition and its new association with the congenital heart disease, some aspects are discussed below with a brief review of the literature (Table 1).

\section{DEVELOPMENT OF AVM}

Beside hepatic artery, the liver can be supplied by a number of extra-hepatic arterial sources including, right or left inferior mesenteric arteries, intercostal arteries, superior mesenteric artery, celiac axis, left gastric artery and the adrenal arteries. The extra-hepatic arterial supply has been demonstrated in about $96 \%$ of patients studied by balloon occlusion of the main hepatic artery [11]. These extra-hepatic arteries remain dormant under normal conditions. However, one or more of these can become enlarged in patients with hepatic vascular malformations or tumors. This was true in our first case as the course of the abnormal feeding artery to the AVM represented most probably one of the minor twigs arsing from the abdominal aorta. But in our second case the feeding artery represented a dilated and tortuous right internal mammary artery arising from the innominate artery. This was an unusual finding as the left or the right internal mammary arteries do not normally contribute to the extra-hepatic arterial supply. To our knowledge internal 
mammary artery feeding a hepatic AVM has not been reported so far. Moreover, though the innominate artery is derived from the neural crest, we did not encounter any other neural crest anomaly in our case. Finally an association of neural crest anomaly with Down syndrome is not documented and needs further elaboration.

Table 1. Review of the literature.

\begin{tabular}{|c|c|c|c|c|c|c|}
\hline Study & Pts & AVM type & Presentation & Association & Treatment & $\begin{array}{c}\text { Results/ } \\
\text { complications }\end{array}$ \\
\hline \multirow[t]{3}{*}{ Nielsen et al. [12] } & 3 & Cerebral $=1$ & $\mathrm{CHF}$ & NA & NA & NA \\
\hline & & Placental $=1$ & $\mathrm{CHF}$ & NA & NA & NA \\
\hline & & Pulmonary $=1$ & $\mathrm{CHF}$ & NA & NA & NA \\
\hline Israel et al. [13] & 1 & Retro-peritoneal & $\mathrm{CHF}$ & NA & Emb with Evalon & avascular mass \\
\hline \multirow[t]{3}{*}{ Favilli et al. [14] } & 4 & Cerebral = 1 & $\mathrm{CHF}$ & NA & None & Died \\
\hline & & Hepatic $=2$ & $\mathrm{CHF}$ & NA & Medical & Improved \\
\hline & & Pulmonary $=1$ & $\mathrm{CHF}$ & NA & embolisation & Died months later \\
\hline $\begin{array}{l}\text { Subramanyam et al. } \\
\text { [15] }\end{array}$ & 1 & Hepatic & $\mathrm{CHF}$ & None & coil embolisation & Resolution \\
\hline \multirow[t]{4}{*}{ Chavan et al. [16] } & 15 & Hepatic vascular & Abdominal $=5$ & HНT & $\begin{array}{l}\text { Emb with PVA } \\
\text { steel/platinum } \\
\text { microcoils }\end{array}$ & Cholangitis $=1$ \\
\hline & & & $\mathrm{CHF}=11$ & HHT & & Cholecystitis $=3$ \\
\hline & & & Portal HTN $=4$ & HHT & & One death \\
\hline & & & Cirrhosis = 1 & HHT & & \\
\hline Costa et al. [17] & 1 & Hepatic & $\mathrm{CHF}$ & NA & Coil embolisation & Resolution \\
\hline Mejides et al. [18] & 1 & Hepatic Vascular & Fetal CHF & NA & $\begin{array}{c}\text { Hydrocortisone in } \\
\text { UV }\end{array}$ & Resolution \\
\hline \multirow[t]{5}{*}{ Knudson et al. [19] } & 156 & Cerebral $=86$ & CHF (67\%) & & $\begin{array}{c}\text { Medical and } \\
\text { surgical }\end{array}$ & Mortality $=67 \%$ \\
\hline & & Hepatic $=61$ & CHF (48\%) & & $\begin{array}{l}\text { Medical and } \\
\text { surgical }\end{array}$ & Mortality $=55 \%$ \\
\hline & & & $\begin{array}{c}\text { Abd. Mass }= \\
67 \%)\end{array}$ & & & \\
\hline & & Pulmonary $=14$ & CHF (67\%) & & $\begin{array}{l}\text { Medical and } \\
\text { surgical }\end{array}$ & Mortality $=43 \%$ \\
\hline & & & Cyanosis (43\%) & & & \\
\hline Chavan et al. [20] & 5 & Hepatic vascular & CHF, Portal HTN & HHT & $\begin{array}{l}\text { Embolisation } \\
\text { (PVA/coils) }\end{array}$ & $\begin{array}{c}\text { Ischemic } \\
\text { Cholangitis }=1\end{array}$ \\
\hline Hazebroek et al. [21] & 2 & Hepatic & $\begin{array}{c}\text { Abdominal angina } \\
\text { CHF,Abd.Distensi } \\
\text { on } \\
\text { Portal HTN }\end{array}$ & Hemangioma & Surgical ligation & Resolution \\
\hline Valerie et al. [22] & 1 & hepatic & Portal HTN & Small PDA, VSD & Coil embolisation & Resolution \\
\hline Whiting et al. [23] & 2 & Hepatic & Abdominal pain & HHT & $\begin{array}{c}\text { Embolisation with } \\
\text { PVA }\end{array}$ & Both died later \\
\hline Chen et al. [24] & 1 & hepatic & Abdominal pain & $\begin{array}{c}\text { Intrahepatic } \\
\text { Biloma }\end{array}$ & Surgical ligation & $\begin{array}{l}\text { Progression of } \\
\text { Biloma }\end{array}$ \\
\hline Alexander et al. [25] & 1 & hepatic & $\begin{array}{c}\text { Persistant Pul. } \\
\text { HTN }\end{array}$ & NA & Coil embolisation & Resolution \\
\hline Hisamatsu et al. [26] & 1 & Hepatic & Epistaxis, dyspnea & $\begin{array}{l}\text { Osler-Weber- } \\
\text { Rendu }\end{array}$ & Coil embolisation & Cholangitis \\
\hline & & & & & & $\begin{array}{c}\text { Hepatic } \\
\text { failure/death }\end{array}$ \\
\hline Prokurat et al. [27] & 17 & Hepatic vascular & $\begin{array}{l}\text { CHF in most } \\
\text { cases }\end{array}$ & Hemangiomas & $\begin{array}{l}\text { Surgical lobec- } \\
\text { tomy }\end{array}$ & Resolution \\
\hline Akita et al. [28] & 1 & Abdominal wall & $\mathrm{CHF}$ & Aneurysmal PDA & Surgical ligation & Liver dysfunction \\
\hline
\end{tabular}

Abreviations. $\mathrm{Abd}=$ abdominal, $\mathrm{CHF}=$ congestive heart failure, $\mathrm{Emb}=$ embolisation, $\mathrm{HHT}=$ hereditary hemorrhagic telangiectasia, $\mathrm{HTN}=$ hyper tension, $\mathrm{NA}=$ not available, $\mathrm{PDA}=$ patent ductus arteriosus, $\mathrm{Pul}=$ pulmonary, $\mathrm{PVA}=$ pollyvinyl alcohol, $\mathrm{UV}=$ umbilical vein, $\mathrm{VSD}=$ ventricular septal defect. 


\section{DIAGNOSING AN AVM}

A cerebral, pulmonary or retro-peritoneal arterio-venous malformation should be suspected in newborns if a bruit or soft a continuous murmur is heard over the skull, chest or the abdomen respectively. Also, an AVM should be included in the differential diagnosis in a newborn or an infant who had unexplained CHF in the setting of normal echocardiogram. Retrospectively thinking, we believe that an AVM should be suspected in a patient who has relatively high systemic saturation for a single ventricle physiology, as in our first case. A keen review of the literature has also confirmed CHF as one of the main presenting feature in majority of the studies [12-20]. Other uncommon modes of presentation are portal hypertension [16,20,21], abdominal pain, mass, ischemia or distension [16,19-24], primary pulmonary hypertension [25] and bleeding episodes [26]. One of our cases presented in CHF and the other was diagnosed incidentally during diagnostic cardiac catheterization. Echocardiographic evaluation with colour flow mapping and pressure doppler helps further in diagnosing an AVM. Finding of an abnormal flow reversal in the aorta raises the possibility of AVM. Advanced radiological techniques including un-enhanced Computed Tomography (CT) and Magnetic Resonance Imaging (MRI) are the useful tools in confidently distinguishing an AVM from other abnormal vascular connection including hemangiomas. Angiography during cardiac catheterization helps not only in exact delineating the feeder and draining vessels but also can help in trans-catheter occlusion, if indicated.

\section{AGE OF PRESENTATION}

Antenatal diagnosis of a hepatic AVM has already been reported [18]. Postnataly a hepatic AVM can present during neo-natal period $[12,14,15,17,20,25,27,28]$ or during infancy $[6,12,13,19]$. It can also present during childhood [21] especially in the setting of hereditary hemorrhagic talengiectasia $[29,30]$ or even during adult life $[20,23,24,26]$. One of our patients presented during neonatal period (case \#2) in respiratory distress due to high output CHF and in the other patient the hepatic AVM was incidentally discovered during cardiac catheterisation. This is in accordance with the study by Prokurat and colleagues [27], who have shown that patients presenting during neonatal period are almost always symptomatic as compared to those who present during infancy.

\section{ASSOCIATION OF HEPATIC AVM AND CONGENITAL HEART DISEASE}

Hepatic AVMs have been described in association with hereditary hemorrhagic talengiectasias $[16,20,23]$ or intra-hepatic tumors [22,24]. In an adult patient [26] an association of hepatic AVM and Osler-Weber-Rendu Disease has also been described. To the best of our knowledge there has been only one report [21] describing the association of hepatic AVM with a congenital heart disease: a patent ductus arteriosus (PDA) and multiple ventricular septal defects (VSD). Though there is another report describing the presence of a PDA aneurysm in a patient who had abdominal AVM, ours is the first report describing an association of hepatic AVM and cyanotic congenital heart disease. This association is, not only of clinical significance but also has therapeutic implications, as CHD is the major cause of CHF during neonatal period and early infancy and one should keep in mind an AVM as an additional cause of high output CHF in refractory cases who do not respond to usual antifailure therapy or do not show improvement after transcatheter or surgical intervention for the primary cardiac defects.

\section{TREATMENT OPTIONS}

Therapeutic options for symptomatic AVMs include transcatheter embolisation or surgical ligation of hepatic artery or surgical hepatic lobectomy or liver transplantation in the advanced cases. Embolotherapy with Polyvinyl Alcohol has been described by Chavan et al., and whiting and colleagues $[16,20,23]$, while Ivalon particles were used for the same purposes by Israel et al. [13]. While many devices including non-detachable Gianturco coils, detachable coils, Aga vascular plugs, and AGA PDA occluders are now available for embolisation of vascular malformations and fistulas, and can be used for this purpose depending upon the location and the size of the malformations. Transcatheter coil embolisation has been described by many studies also $[15,21,25,26]$. We opted for Gianturco coils, because of these being available to us in multiple sizes, our expertise to use these because of frequent use and successful results in the literature $[21,25,26]$. Surgical ligation of hepatic artery has also been described by some $[22,24]$. We used transcatheter approach through femoral artery for coil embolisation of AVM, though trans-umbilical approach has also been described by Costa and colleagues [17]. All of the studies have described acceptable results with the occlusion of AVM and resolution of the symptoms.

\section{COMPLICATIONS AFTER TREATMENT}

Cholangitis in one and cholecystitis in another three patients has been described by Chavan et al. [16] out of 15 patients (one patient died due to the procedure), while sepsis has been described in 2 patients after the same 
procedure by Whiting et al. [23]. Both of the patients died 4 and 15 months after the procedure. Intrahepatic cholangitis has been described after coil embolisation of the hepatic artery in one patient by Hisamatsu and colleagues [26]. The patient ultimately died a year later due to hepatic dysfunction. Ischemic cholangitis has also been reported after the same procedure in one out of 5 patients by Chavan and colleagues [20] while one of their patients died 7 months after the procedure due to sepsis. Apart from theses two reports none has reported any complications. Surgical ligation has generally been described as risk free, and only one report has described progression of the disease even after the procedure [24]. We did not encounter any immediate or early follow-up complications, so far.

\section{CONCLUSIONS}

Hepatic AVMs are rare conditions in children and a high index of suspicion is required to diagnose these especially in those cases who present with either unexplained or refractory high output $\mathrm{CHF}$ or in those who had relatively higher systemic saturation in the setting of complex congenital heart disease with single ventricle physiology. Many treatment options are available with acceptable results. Transcatheter coil embolisation is safe and effective for this purpose. Care should be exercised to avoid ischemic changes after either transcatheter embolisation or surgical ligation of the hepatic artery. The importance of these reports is not only the fact that such an association has not been reported before and expands our clinical differential, but also these give us clues to a deeper insight in the mechanism of cardiovascular development.

\section{REFERENCES}

[1] Gallego, C., Miralles, M., Marin, C., Muyor, P., Gonzales, G. and Garcia-Hidalgo, E. (2004) Congenital hepatic shunts. RadioGraphics, 24(3), 755-772.

[2] Mulliken, J.B. and Glowacki, J. (1982) Hemangiomas and vascular malformations in infants and children: A classification based on endothelial characteristics. Plastic Reconstruction Surgery, 69(3), 412-422.

[3] Shulman, R.J., Holmes, R., Ferry, G.D. and Finegold, M. (1986) Splanchnic bed vascular malformations and the development of portal hypertension. Journal of pediatric Surgery, 21(4), 355-357.

[4] Dehner, L.P. (1978) Hepatic tumors in pediatric age group: A distinctive clinicopathologic spectrum. Pediatric Pathology, 4, 217-268.

[5] Weinberg, A.G. and Finegold, M.J. (1983) Primary hepatic tumors of childhood. Human Pathology, 14(6), 512-537.

[6] Boon, L.M., Burrows, P.E., Paltiel, H.J., Lund, D.P., Ezekowitz, R.A., Folkman, J. and MulliKen, J.B. (1996)
Hepatic vascular anomalies in infancy: A 27 years experience. Journal of Pediatrics, 129(3), 346-354.

[7] Folkman, J., Mulliken, J. and Ezikowitz, A. (1997) Angiogenesis and hemangiomas, In: Oldman, K., Colombani, P. and Foglia, R., Eds., Surgery of infants and children. Lippincott-Raven Publishers, Philadelphia.

[8] Mulliken, J.B. and Young, A.Y. (1988) Vascular birthmarks: hemangiomas and malformations. W. B. Saunders, Philadelphia.

[9] Paltiel, H.J, Patriquin, H.B., Keller, M.S., Babcock, D.S. and Leithiser, R.E. (1992) Infantile hepatic hemangioma: Doppler US. Radiology, 182(3), 735-742.

[10] Stanley, P., Geer, G.D., Miller, J.H., Gilsanz, V., Landing, B.H. and Boechat, I.M. (1989) Infantile hepatic hemangioma: clinical features, radiological investigations, and treatment of 20 patients. Cancer, 64(4), 936-949.

[11] Takeuchi, Y., Arai, Y., Inaba, Y., Ohno, K., Maeda, T. and Itai, Y. (1998) Extrahepatic arterial supply to the liver: Observation with a unified CT and angiography system during balloon occlusion of the proper hepatic artery. Radiology, 209(1), 121-128.

[12] Nielsen, G. (1984) Arterio-venous malformations as a cause of congestive heart failure in the newborn and infant. Three cases with different haemodynamic mechanisms. European Journal of Paediatrics, 142(4), 298300.

[13] Israel, P.G., Armstrong, B.E., Effman, E.L., Newman, G.E. and Anderson, P.W. (1993) Retroperitoneal arteriovenous malformation, a rare cause of heart failure in infancy: Consideration of therapeutic approach. Pediatric Cardiology, 14(1), 49-52.

[14] Favilli, S., De Simone, L., Scarano, E., Repetto, T. and Manetti, A. (1995) Congenital arteriovenous malformations: an unusual cause of heart failure at birth and during the first months of life. G Italian Cardiology, 25(7), 88-90.

[15] Subramanyam, R., Narayan, R., da Costa, D., Derweesh, A. and Khusaiby, S.M. (2001) Transcatheter coil occlusion of hepatic arteriovenous malformation in a neonate. Indian Heart Journal, 53(6), 782-784.

[16] Chavan, A., Caselitz, M., Gratz, K.F., Lotz, J., Kirchhoff, T., Piso, P., Wagner, S., Manns, M. and Glalanski, M. (2004) Hepatic artery embolisation for treatment of patient with hereditary hemorrhagic telangiectasia and symptomatic hepatic vascular malformations. European Radiology, 14(11), 2079-2085.

[17] Costa, S., de Carolis, M.P., Di Stasi, C., Papacci, P., Fusco, F. and Romagnoli, C. (2006) Transubilical embolisation of hepatic arteriovenous malformation in a neonate with heart failure. European Journal of Pediatrics, 165(11), 897-909.

[18] Mejides, A.A., Adra, A.M., O’Sullivan, M.J. and Nicholas, M.C. (1995) Prenatal diagnosis and therapy for a fetal hepatic vascular malformation. Obstetric and $G y$ necology, 85(5), 850-853.

[19] Knudson, R.P. and Alden, E.R. (1979) Symptomatic arteriovenous malformation in infants less than 6 months of age. Pediatrics, 64(2), 238-241.

[20] Chavan, A., Galanski, M., Wagner, S., Caselitz, M., Schlitt, H.J., Gratz, K.F. and Manns, M. (1998) Hereditary hemorrhagic telangiectasia: Effective protocol for embolisation of hepatic vascular malformations-experience in 5 
patients. Radiology, 209(3), 735-739.

[21] Marchand, V., Uflacker, R., Baker, S.S. and Baker, R.D. (1999) Congenital hepatic arterioportal fistula in a 3year-old child. Journal of Pediatric Gastroenterology and Nutrition, 28(4), 435-441.

[22] Hazebroek, F.W., Tibboel, D., Robben, S.G., Bergmeyer, J.H. and Molenaar, J.C. (1995) Hepatic artery ligation for hepatic vascular tumors with arteriovenous and arterioportal venous shunts in the newborn: successful management of two cases and review of literature. Journal of Pediatric Surgery, 30(8), 1127-1130.

[23] Whiting, J.H. Jr, Korzenik, J.R., Miller, F.J. Jr, Pollack, J.S. and White, R.I. (2000) Fatal outcome after "mbolisation" for hepatic arteriovenous malformations of the liver in two patients with hereditary hemorrhagic telangiectasia. Journal of Vascular Interventional Radiology, 11(7), 855-858.

[24] Chen, C.H., Yang, P.M., Sheu, J.C., Huang, G.T., Tsang, Y.M., Lee, P.H. and Chen, D.S. (1999) Intrahepatic bilomas associated with hepatic arteriovenous malformation. Hepatogastroenterology, 46(25), 443-447.

[25] Alexander, C.P., Sood, B.G., Zilberman, M.V., Becker, C. and Bedard, M.P. (2006) Congenital hepatic arteriovenous malformation: An unusual cause of neonatal persistant pulmonary hypertension. Journal of Perinatology,
26(5), 316-318

[26] Hisamatsu, K., Ueeda, M., Ando, M., Koike, K., Matsuo, N., Matsu-Ura, K., Ueda, H., Hirohata, M. and Imai, M. (2000) Peripheral arterial coil embolisation for hepatic arteriovenous malformation in Osler-Weber-Rendu disease; useful for controlling high output heart failure, but harmful to the liver. Internal Medicine, 38(8), 962-968.

[27] Prokurat, A., Kluge, P., Chrupek, C., Kosciesa, A. and Rajszys, P. (2002) Hemangioma of the liver in children: Proliferating vascular tumor or congenital vascular malformation. Medical Pediatric Oncology, 39(5), 524-529.

[28] Akita, H., Ohta, A., Furukawa, S., Egawa, Y., Kawahito, T., Horike, K., Ohshio, T. and Matsumura, C. (1995) Newborn with congenital arteriovenous fistula of the abdominal wall complicated by a ductus arteriosus. $P e$ diatric Cardiology, 16(5), 235-238.

[29] Burrows, P.E., Dubios, J. and Kassarjan, A. (2001) Pediatric hepatic vascular anomalies. Pediatric Radiology, 31(8), 533-545.

[30] Buscarini, E., Buscarini, L., Civardi, G., Arruzzoli, S., Bossalini, G. and Piantanida, M. (1994) Hepatic vascular malformations in hereditary hemorrhagic telangiectasia: Image findings. Americam Journal of Roentgenology, 163(5), 1105-1110. 